\title{
Alterações e expectativas vivenciadas pelos indivíduos com lesão raquimedular e suas famílias
}

\author{
CHANGES AND EXPECTATIONS EXPERIENCED BY INDIVIDUALS \\ WITH SPINAL CORD INJURY AND THEIR FAMILIES
}

\author{
ALTERACIONES Y EXPECTATIVAS VIVENCIADAS POR LOS INDIVIDUOS \\ CON LESIÓN RAQUIMEDULAR Y SUS FAMILIAS
}

Daniele Aparecida Venturini', Maria das Neves Decésaro", Sonia Silva Marcon"I'

\section{RESUMO}

O objetivo do estudo foi identificar as principais alterações decorrentes da presença de um indivíduo com lesão medular no convívio familiar; bem como as expectativas relacionadas com essa condição. Trata-se de um estudo quali-quantitativo desenvolvido junto à 32 famílias de indivíduos com lesão raquimedular no município de MaringáPR. Na análise dos dados, surgiram três categorias: Relação com os serviços de saúde; Relacionamento familiar e Expectativas em relação ao tratamento. Os resultados nos permitem inferir que as mudanças advindas com o trauma raquimedular alteram não apenas a vida dos indivíduos, mas a dinâmica e o relacionamento familiar. Por isso, considera-se fundamental que a família desses indivíduos seja assessorada em suas dificuldades para que possa prover a continuidade da assistência e contribuir para a melhoria da qualidade de vida de seus membros portadores de lesão raquimedular, ampliando as perspectivas de vida e as expectativas relacionadas ao tratamento.

\section{DESCRITORES}

Traumatismos da medula espinhal.

Relações familiares.

Acesso aos serviços de saúde.

\section{ABSTRACT}

This study was aimed at identifying the main changes resulting from the presence of an individual with spinal cord injury in family life, as well as the expectations regarding this condition. It was developed with 32 families in the city of Maringá, State of Paraná. From data analysis three categories emerged: relations with health services; family relations; and expectations regarding the treatment. Results suggest that the changes after a spine cord injury alter not only the individual's life, but also the family's routine and its internal relations. For that reason it is considered vital for families to get outside support for the difficulties they face so that they can ensure continuous assistance and contribute to a better life quality of their members with spinal cord injury, increasing their life expectancy and treatment prospects.

\section{KEY WORDS}

Spinal cord injuries.

Family relations.

Health services accessibility.

\section{RESUMEN}

El objetivo del estudio fue identificar las principales alteraciones resultantes de la presencia de un individuo con lesión medular en el convívio familiar; bien como las expectativas relacionadas con esa condición. Se trata de un estudio cualitativo-cuantitativo desarrollado junto a las 32 familias de individuos con lesión raquimedular en la ciudad de Maringá, en el estado de Paraná. En el análisis de los datos, surgieron tres categorías: Relación con los servicios de salud; Relación familiar y Expectativas en relación al tratamiento. Los resultados nos permiten inferir que los cambios acrecidos con el trauma raquimedular alteran no apenas la vida de los individuos, más la dinámica y la relación familiar. Por eso, se considera fundamental que la familia de esos individuos sea asesorada en sus dificultades para que pueda proveer la continuidad de la asistencia y contribuir para la mejoría de la calidad de vida de sus miembros portadores de lesión raquimedular, ampliando las perspectivas de vida y las expectativas relacionadas al tratamiento.

\section{DESCRIPTORES}

Traumatismos de la médula espinal.

Relaciones familiares.

Accesibilidad a los servicios de salud.
Enfermeira Mestranda em Enfermagem da Universidade Estadual de Maringá (UEM), Maringá, PR Brasil. Bolsista CAPES. danieleventurini@ bol.com.br

II Enfermeira. Doutoranda em Enfermagem Fundamental da Escola de Enfermagem de Ribeirão Preto (EERP-USP). Professora do Departamento de Enfermagem da Universidade Estadual de Maringá (UEM), Maringá, PR Brasil.saudades@ eerp.usp.br

III Enfermeira. Professora Doutora do Departamento de Enfermagem da Universidade Estadual de Maringá (UEM), Maringá, PR Brasil. Coordenadora do Mestrado em Enfermagem. ssmarcon@uem.br 


\section{INTRODUÇÃO}

O número de pessoas tetraplégicas ou paraplégicas por lesão de medula espinhal vem aumentando significativamente nas últimas décadas e atualmente estima-se que de 30 a 40 pessoas/milhão/ano sofrem lesão, o que equivale no Brasil a aproximadamente 6000 novos casos por ano ${ }^{(1)}$. Este aumento se deve principalmente às lesões traumáticas (80\%) provocadas por ferimentos com arma de fogo, acidentes automobilísticos, mergulhos e quedas. Entre as causas não traumáticas (20\%), destacam-se os tumores, infecciosas, vasculares e degenerativas ${ }^{(1)}$.

Esta é uma realidade vivenciada em diferentes pontos do país, em Maringá - PR, por exemplo, tem sido observado um crescimento assustador no número de acidentes automobilísticos, repercutindo nos índices de mortalidade por causas externas e no aumento dos casos de lesão medular ${ }^{(2-4)}$.

O traumatismo raquimedular, apesar de não se constituir em uma doença propriamente dita, agride fisicamente o corpo e de forma inesperada limita ou mesmo anula o uso e o controle das funções orgânicas. As perdas da condição saudável, de papéis e responsabilidades provocam mudanças nos hábitos e no estilo de vida do indivíduo e exige que o mesmo atribua novos significados à sua existência, adaptandose às limitações físicas e às novas condições geradas $^{(5)}$.

No entanto, para conseguir se adaptar e ainda aprender a viver de forma diferente, com constante superação das alterações no modo de vida, faz-se necessário, entre outros, seguir orientações e participar de um programa de reabilitação ${ }^{(5)}$, o que exige da pessoa com deficiência e seus familiares abdicação de momentos de lazer ou a necessidade de priorizar hábitos ou atividades mais condizentes com a nova situação, muitas vezes alterando a rotina de vida de toda a família ${ }^{(5)}$.

Esta condição, portanto, traz inúmeras repercussões para o indivíduo, a família e a sociedade e seu enfrentamento, assim como ocorre nos casos de doença, leva a família a organizar-se e a redimensionar sua vida para melhor compreender o indivíduo e aprender a conviver com a doença e as implicações dela decorrentes ${ }^{(6)}$. Destarte, a família é, ao mesmo tempo, elemento indispensável no cuidado e um ente a ser cuidado, de tal forma que o paciente já não pode ser visto de forma isolada, é preciso que se considere pelo menos seu contexto mais próximo que é a família ${ }^{(7)}$, lembrando que a presença, o carinho e o apoio da família são fundamentais ao ser cuidado ${ }^{(8)}$.

O ambiente familiar, portanto, consiste em espaço indispensável à garantia da sobrevivência, desenvolvimento e proteção integral de seus membros, além de propiciar os aportes afetivos e materiais necessários ao desenvolvimento e bem-estar de seus componentes. É na família que são absorvidos os valores éticos e humanitários e onde se aprofundam os laços de solidariedade ${ }^{(9)}$.

Por isso cada família deve ser compreendida como única pertencente a um contexto social e cultural específico que determina sua maneira de viver e adoecer, sendo que este último interfere na dinâmica familiar fazendo com que seus efeitos sejam percebidos de imediato. Para alguns autores ${ }^{(10)}$, é nos momentos de modificação em sua estrutura ou dinâmica que a família passa a ter maior significado, como ocorre na doença, quando há mudanças nas condições de vida e saúde de seus membros.

O envolvimento da família no processo de reabilitação é fundamental, no sentido de participar e dar continuidade ao que será implementado pela equipe assistencial ${ }^{(11)}$. Por isto, cuidar desses pacientes exige conhecer suas famílias, que constituirão o principal apoio durante o processo de doença e reabilitação, para possibilitar uma assistência mais humana e efetiva.

Para tanto, ao mesmo tempo em que a família deve ser concebida como co-participante do processo de cuidar em todos os momentos, cabe aos profissionais identificar as situações nas quais ela precisa ser melhor assessorada $^{(7)}$; ela também deve, enquanto unidade de saúde, ser cuidada e isto exige que se conheça como essa família cuida, identificando suas dificuldades e suas forças. Somente assim o profissional, com seu saber técnico, científico e humanístico, poderá ajudar a família a agir de forma a atender às necessidades de seus membros ${ }^{(7)}$.

Assim, o objetivo deste trabalho é descrever as principais alterações ocorridas na relação familiar com a introdução do indivíduo com lesão medular em seu convívio e relatar as expectativas desses indivíduos frente sua nova condição de vida, para poder direcionar não apenas as ações dos profissionais mas da sociedade como um todo.

\section{MÉTODO}

A pesquisa foi descritiva exploratória, de natureza qualiquantitativa, desenvolvida junto a 32 pessoas com lesão medular (LM) residentes no município de Maringá-PR, identificadas, num primeiro momento, a partir do cadastro do Centro de Vida Independente (CVI), e num segundo, a partir de informações coletadas junto das 57 equipes do Programa de Saúde da Família (PSF) instaladas nas 23 unidades básicas de saúde (UBS), o que cobria na época $70 \%$ da população do município. 
Os dados foram coletados no período de setembro a novembro de 2003, utilizando como técnica a entrevista semiestruturada e como estratégia a visita domiciliar. As visitas foram previamente agendadas e todas as pessoas identificadas aceitaram participar da pesquisa. $\mathrm{O}$ instrumento utilizado na coleta de dados foi um questionário do tipo misto, constituído de 54 questões distribuídas em quatro partes: características sócio demográficas do indivíduo e sua família, história do acidente e do tratamento recebido, dependências e limitações e alterações na rotina de vida e nas relações familiares.

As respostas dos informantes foram registradas integralmente no momento das entrevistas e como forma de validação de seu conteúdo, elas foram lidas para os informantes que concordavam com a transcrição de seu conteúdo ou as complementava e/ou corrigiam quando achavam necessário.

$\mathrm{Na}$ análise dos dados, adotou-se o referencial de análise temática de conteúdo ${ }^{(12)}$, levando em consideração única e exclusivamente as respostas emitidas pelos informantes. Assim, após leitura e escuta flutuante realizada pelos autores, os dados foram refletidos, visando a escanção e o reagrupamento em sistema de categorias. Desta forma, por meio da identificação de temas significativos a serem interpretados, buscamos identificar as situações mais freqüentes e também aquelas vivenciadas especificamente por cada um dos informantes do estudo em relação a: 1) características dos indivíduos e suas famílias, 2) relação com os serviços de saúde, 3) relacionamento familiar e 4) expectativas quanto ao tratamento.

A solicitação para participar no estudo foi feita pessoalmente, ocasião em que foram informados os objetivos do estudo e o tipo de participação desejada, além de ser garantido anonimato das informações. $\mathrm{O}$ estudo respeitou os preceitos éticos disciplinados pela Resolução n. ${ }^{\circ} 196 / 96^{(13)}$, os informantes assinaram o termo de consentimento livre e esclarecido e o projeto foi aprovado pelo Comitê de Ética em Pesquisa com Seres Humanos da Universidade Estadual de Maringá.

Tabela 1 - Distribuição em número e percentual dos indivíduos com lesão medular, segundo o grau de dependência para as atividades da vida diária - Maringá - PR - 2002

\begin{tabular}{|c|c|c|c|c|c|c|}
\hline \multirow[b]{2}{*}{ Atividades } & \multicolumn{2}{|c|}{ Independente } & \multicolumn{2}{|c|}{ Parcialmente dependente } & \multicolumn{2}{|c|}{ Totalmente dependente } \\
\hline & $\mathrm{n}^{\mathrm{o}}$ & $\%$ & $\mathrm{n}^{\mathrm{o}}$ & $\%$ & $\mathrm{n}^{\mathrm{o}}$ & $\%$ \\
\hline Troca de roupas & 14 & 43,8 & 6 & 18,8 & 12 & 37,5 \\
\hline Ingesta líquida & 26 & 81,2 & 4 & 12,5 & 2 & 6,2 \\
\hline Ingesta sólida & 22 & 68,7 & 6 & 18,8 & 4 & 12,5 \\
\hline Transferência/ Motilidade & 15 & 46,9 & 12 & 37,5 & 5 & 15,6 \\
\hline Locomoção & 6 & 18,8 & 16 & 50,0 & 10 & 31,2 \\
\hline Eliminação & 14 & 43,8 & 6 & 18,8 & 12 & 37,5 \\
\hline Higiene oral & 24 & 75,0 & 4 & 12,5 & 4 & 12,5 \\
\hline Higiene corporal & 15 & 46,9 & 9 & 28,1 & 8 & 25,5 \\
\hline
\end{tabular}

Nota: Os percentuais foram calculados com base nos 32 indivíduos com lesão medular em estudo.

\section{RESULTADOS}

\section{Características dos indivíduos e suas famílias}

Das 32 pessoas entrevistadas, $27(84,4 \%)$ eram do sexo masculino, $25(78,1 \%)$ casadas, sendo que $50,0 \%$ e $30 \%$ ocupavam respectivamente a posição de pais e filhos na família. Quanto à escolaridade, 71,9\% (23) tinham o ensino fundamental completo ou incompleto, $18,8 \%$ (6) o ensino médio completo ou incompleto e apenas um $(3,1 \%)$ o ensino superior incompleto. Este tipo de acidente foi mais freqüente em adultos jovens masculino, visto que $50 \%$ deles sofreram o trauma com idade entre 19 e 38 anos, no sexo feminino ele foi mais freqüente após os 30 anos.

É interessante observar que embora à época do acidente $78,1 \%$ dos indivíduos fossem casados, na época da entrevista apenas $43,8 \%$ deles assim o permaneciam, revelando um importante aspecto da problemática vivenciada por essas pessoas, especialmente as do sexo feminino, que muitas vezes se vêem abandonadas por seus cônjuges. Dos sete indivíduos que eram solteiros $(21,9 \%)$; apenas um casou-se após o acidente e a esposa assumiu o papel de cuidadora.

As características encontradas são similares às de outros trabalhos, especialmente no que se refere à predominância do sexo masculino, época de ocorrência do acidente $^{(14-15)}$ e escolaridade ${ }^{(14,16-18)}$.

Antes da lesão, a maioria (81,3\%) trabalhava regularmente e contribuía com a renda familiar, e após, só quatro indivíduos $(12,5 \%)$ trabalham (como artesão, vendedor ambulante ou voluntário) e dois (6,3\%) estudam. A impossibilidade para o trabalho constitui preocupação não só pela necessidade de adquirir renda, mas de assumir um papel social como resgate da identidade do $\mathrm{LM}^{(18)}$.

No que se refere às condições de vida, constatou-se que apenas $12,5 \%$ dos indivíduos em estudo não são dependentes de cuidados. Tal fato revela a necessidade de um cuidador próximo para atender as limitações daqueles que dependem parcial ou totalmente dos cuidados de outrem. A Tabela 1 mostra essas diferenças no grau de dependência. 
Quanto às condições familiares identificou-se que mais da metade dos indivíduos $(56,2 \%)$ pertencem a famílias do tipo nuclear, $31,3 \%$ às do tipo extensa, três indivíduos $(9,4 \%)$ vivem sozinhos e um vive em família do tipo alternativa ${ }^{(19)}$. A maior parte deles vive em arranjos domésticos constituídos de 2 a 3 membros $(40,6 \%)$ ou de 4 a $6(40,6 \%)$, mas três deles $(9,4 \%)$ coabitam com mais 7 membros. Além disso, metade das famílias tinha uma renda familiar de 1 a 3 salários-mínimos (SM), 40,6\% auferiam renda de 4 a 6 SM e em $9,4 \%$ a renda era superior a sete salários-mínimos, sendo que seis $(18,7 \%)$ indivíduos ainda não haviam conseguido aposentadoria, o que não lhes permitia contribuir na complementação da renda familiar. Em $68,8 \%$ das famílias a moradia era própria, em $18,7 \%$ alugada e em $12,5 \%$ cedida.

No que se refere à condição econômica das vítimas, alguns autores ${ }^{(14)}$ afirmam que até meados da década de 1980 , os indivíduos lesados pertenciam à classe social de melhor nível socioeconômico, com renda familiar acima de $15 \mathrm{SM}$, e após esse período passou-se a observar uma queda no padrão econômico das vítimas deste tipo de trauma, em decorrência das alterações socioeconômicas que ocorreram no país, associadas à facilidade - por meio de financiamentos por exemplo -, na aquisição de bens de consumo, como carros e motocicletas.

O advento da nova condição - a de ser lesado medular -, além da dependência, desencadeia também uma série de problemas físicos e fisiológicos tais como: presença de úlceras de pressão, infecção urinária, espasticidade e deformidades em graus variados conforme o comprometimento, desencadeando inúmeras dificuldades e/ou limitações, como por exemplo: a dificuldade de inserção da pessoa com deficiência no mercado de trabalho e o sentimento de desorientação experimentado perante às expectativas sociais, interferindo em sua imagem corporal e auto-imagem ${ }^{(5)}$.

Além de todos estes aspectos afetados, os indivíduos com lesão medular, como qualquer ser humano, ainda está sujeito a problemas de saúde diversos, os quais podem ou não estar diretamente associados à lesão medular. No presente estudo, 11 indivíduos apresentavam outros problemas de saúde (diabetes mellitus, osteomielite, hipertensão arterial, câncer de bexiga, convulsão, osteoporose, disritmia cardíaca, depressão, sinusite).

Pessoas com lesão medular trazem consigo uma série de aspectos que demandam cuidados e atenção, sendo necessária uma abordagem holística que possibilite a detecção de possíveis problemas tanto de ordem física como de saúde já existentes ou advindos com a lesão medular.

O cuidador por sua vez constitui peça fundamental na difícil tarefa de proporcionar uma vida saudável ${ }^{(20)}$ e com menor comprometimento funcional. Para tanto, necessitam de capacitação adequada, pois a manutenção da saúde desses indivíduos exige um conhecimento sobre as alterações decorrentes da lesão medular, e principalmente das complicações, assim como a compreensão do contexto psicológico e da dinâmica familiar.

As dificuldades mais frequentemente enfrentadas no cotidiano dos indivíduos com LM estão relacionadas à questão econômica $(37,5 \%)$ e à dependência do outro $(28,1 \%)$. Estas dificuldades se completam, pois ser dependente exige cuidados, o que muitas vezes priva outra pessoa, além do LM, de contribuir economicamente para o sustento da família. Além disso, foram apontadas dificuldades relacionadas com ausência de cidadania - como a falta de estrutura física da cidade $(18,8 \%)$, que inclui a falta de transporte, de emprego e de atividade física e o preconceito $(6,2 \%)$.

\section{A relação com os serviços de saúde}

Apesar das dificuldades financeiras, com relação ao acesso aos serviços de saúde, encontrou-se que quase metade dos indivíduos $(46,9 \%)$ referiu não ter qualquer dificuldade, o que se relaciona ao fato deles utilizarem serviços particulares $(6,2 \%)$ ou por possuírem plano de saúde $(18,7 \%)$. Contudo, uma das pessoas revelou ter enfrentado problemas ao fazer uso de seu plano:

... mesmo tendo plano, a gente enfrenta a demora das consultas [...] o plano de saúde não quis cobrir minha internação quando eu estava com infecção urinária por dizer que era pré-existente, causada pela LM, então entrei na justiça e consegui que cobrissem... (sujeito 9).

Além disso, sete LM $(21,9 \%)$ relatam que apesar de utilizarem o serviço público, não enfrentam qualquer dificuldade, especialmente após a implantação do Programa Saúde da Família (PSF):

Agora com o PSF melhorou muito, porque vem na nossa casa para coletar exames, fazer consulta...(sujeito 27).

Nenhuma, principalmente por causa do PSF (sujeito 15).

É oportuno ressaltar que a estratégia do PSF busca atender as famílias em seu contexto domiciliar, respeitando crenças e valores, com o objetivo de explorar os conhecimentos e os recursos de que a família dispõe. O cuidado dispensado à saúde no domicílio possibilita à equipe de saúde da família conhecer aspectos do cotidiano de vida dos pacientes; o que por sua vez permite a identificação mais efetiva de demandas e potencialidades da família, em um clima de parceria terapêutica. Para isso, concorrem fatores como a humanização do cuidado e o resgate das formas de cuidado baseadas no senso comum e na cultura ${ }^{(21)}$.

As dificuldades relacionadas com os serviços de saúde referidas por 17 famílias $(53,1 \%)$ puderam ser organizadas em dois grandes grupos em relação às dificuldades relacionadas:

a) à estrutura do serviço que englobam as manifestações sobre dificuldades de transporte, deficiência na planta física (ausência de rampas), existência de fila para o atendimento e 
escassez no atendimento especializado necessário para os casos de complicações, bem como escassez de outros tipos de procedimentos necessários a um indivíduo com LM, como, por exemplo: consultas com especialistas - neurologistas e urologistas, além de acompanhamento fisioterápico.

A gente enfrenta demora no atendimento, filas, desrespeito com os direitos dos deficientes (sujeito 10).

Fico muito tempo esperando consulta, não consigo tratamento para a osteomielite quando entro em fase aguda, aí tenho que ir para São Paulo no HC (sujeito 9).

b) ao despreparo técnico e humano dos profissionais da área de saúde para prestar assistência ao LM e sua família:

\begin{abstract}
Encontramos dificuldades pelo desconhecimento dos profissionais sobre as conseqüências da LM. A medicina foi feita para as pessoas ditas normais e não para quem tem LM, os hospitais e consultórios não estão adaptados fisicamente e humanamente para receber as pessoas com LM (sujeito 10).
\end{abstract}

Falta de um serviço especializado em LM, com profissionais capacitados (sujeito 30 ).

Estes dados reforçam o quanto é apropriada a preocupação do Ministério da Saúde com a prevenção e assistência às pessoas portadoras de deficiências, cujo objetivo é fortalecer diretrizes que entre outras, visam à promoção da qualidade de vida das pessoas portadoras de deficiência e a capacitação de recursos humanos ${ }^{(22)}$.

O despreparo técnico e humanístico dos profissionais nesta área tem sido apontado como uma grande preocupação por alguns autores ${ }^{(11)}$, pois de forma geral, eles não recebem formação que lhes permita assistir aos indivíduos com esse tipo de lesão e seus familiares de forma segura e competente do ponto de vista técnico e humanitário, em todas as etapas do tratamento.

Uma forma de melhorar esse atendimento pelos serviços de saúde seria facilitar o acesso e oferecer atendimento personalizado, de forma mais acolhedora, no sentido de manter uma relação de vínculo direto com a clientela e estabelecer responsabilidades com relação à manutenção da saúde desta comunidade ${ }^{(5)}$.

\section{Relacionamento familiar}

A presença da deficiência e incapacidade no contexto familiar altera a dinâmica das relações e a complexidade de suas interações. As famílias que vivenciam essa situação passam por transformações no decorrer do tempo e as que mais se sobressaem são as marcadas pela presença de crises. Diante da necessidade de acolher o indivíduo com LM e apoiar seu processo de recuperação e reabilitação, cada pessoa da família individualmente e respeitando suas características peculiares, busca manter a integridade física e emo- cional do grupo, desenvolvendo, favorecendo ou fortalecendo as relações familiares.

As mudanças sejam negativas ou positivas implicam no estabelecimento de uma nova rotina para o sistema familiar. Os pontos de transição na família são considerados estressores, pois envolvem conflito e acomodação a um novo funcionamento, já que as velhas normas são questionadas. As mudanças envolvem perdas das situações conhecidas e estáveis e ganhos que nem sempre são inicialmente percebidos, pois o novo desencadeia incertezas ${ }^{(5)}$. Assim, frente à situação de crise, a família tem chance de repensar valores e formas de se relacionar, propiciando situações de afeto e assistência a todos os membros. Antigos conflitos podem ser resolvidos, pelos sentimentos de união e ajuda mútua que surgem. O contrário também pode acontecer, situações de conflito podem desencadear mais inconstâncias e tornar o relacionamento familiar tenso e incompleto $^{(5)}$.

Percebe-se que a relação familiar comporta características ímpares do ser e viver em família e buscar a sua compreensão requer um despir-se de preconceitos, entendendo-os em sua singularidade como nos são apresentados.

Neste sentido, os resultados revelam que dos 32 entrevistados, $21(65,6 \%)$ referiram que houve algum tipo de alteração na relação interpessoal familiar, sendo positiva, constante ou negativa. Dez indivíduos não se manifestaram e apenas uma pessoa $(3,1 \%)$ relata que convive em um ambiente com muita discussão pelo fato de um membro da família (pai) ser alcoolista, o que dificulta o relacionamento, acarretando principalmente problemas físicos e financeiros.

Dos que consideram mudanças na relação familiar, sete referiram que a relação familiar melhorou, o que percebem através de uma maior união do grupo familiar e também por meio da demonstração de atenção, apoio e paciência.

Acho que após a LM passei a receber mais atenção da família (sujeito 15).

Agora participo mais do dia-a-dia da família (sujeito7).

Fiquei mais próximo da minha família (sujeito 5).

Nove indivíduos referiram que não houve mudança na relação familiar:

Está a mesma coisa, mas me apeguei mais com Deus (sujeito 29).

Passamos a ter mais dificuldade financeira, mas a gente vai levando... (sujeito 25).

Não mudou... a família tem paciência e eu tento contribuir (sujeito 32).

Sempre foi boa (sujeito 10). 
Para cinco indivíduos no entanto, a relação familiar piorou e as mudanças ocorridas são percebidas de forma negativa.

Aumentaram as brigas... acho que depois da LM fiquei mais nervoso, brigo mais (sujeito 1).

Piorou muito, não tem mais conversa (sujeito 26).

Sem sentido na vida... (sujeito 2).

Falta compreensão, todos estão mais nervosos, irritados, dificultando a convivência com a esposa... (sujeito 22).

Antes era melhor... agora parece que tá bloqueado. (sujeito 11).

As mudanças no contexto familiar, após a ocorrência de lesão medular, são muito freqüentes, alguns estudos ${ }^{(23)}$ já identificaram que elas estão presentes em mais da metade dos casos $(63,3 \%)$, sendo identificado com mais freqüência mudanças negativas do que positivas. As mudanças positivas referidas na literatura são: aproximação familiar e dos amigos, maior atenção recebida e o aspecto de ver o mundo de outra forma, entre as negativas, foram referidas entre outras a maior irritação e agressividade.

É importante que haja flexibilidade na estrutura familiar para garantir que os membros desempenhem seus papéis e assumam outros apenas quando for necessário para lidar com as mudanças ocasionadas. Caso contrário, os papéis podem se confundir e a estrutura se torna prejudicada ${ }^{(5)}$.

Na busca de subsídios para entender quais mecanismos a família utiliza para manter-se unida e, constatou-se que em onze famílias $(34,4 \%)$ os sentimentos como o amor, a amizade, o respeito e a cooperação são os que favorecem a união entre os membros, que possibilita sustentar o enfrentamento de situações difíceis:

Tendo amor e respeito um pelo outro vamos vivendo o diaa-dia (sujeito 10).

... tudo pelo amor, o amor nos dá força para viver. (sujeito 9).

Através do amor conseguimos a união e continuamos firmes na luta (sujeito 5).

Dez entrevistados $(31,2 \%)$ relacionam a manutenção desta união por meio da crença em Deus, pela fé, pela oração, enfim pelo fato de terem uma religião:

Tenho força porque participo de grupos de oração, tenho fé em Deus (sujeito 29).

... só através da oração e acreditando em Deus (sujeito 4).

... tendo uma religião, sem ela não daria conta de continuar (sujeito 7).

Eu me apego a Deus (sujeito 14).
A prática do diálogo constante apareceu como principal fator em seis $(18,8 \%)$ relatos. Foram referidos ainda a reunião da família aos domingos, a presença forte da figura do pai e da mãe, e o fato de todos trabalharem em um mesmo local com um só objetivo. Além disso, uma pessoa $(3,1 \%)$ referiu não ter muito contato com os parentes e outra $(3,1 \%)$ preferiu não responder a questão.

Outros autores também constataram que o LM busca ajuda e conforto para superar suas dificuldades junto a Deus, às pessoas de seu convívio, ou mesmo com estranhos ${ }^{(24)}$.

\section{Expectativas quanto ao tratamento}

Diante das alterações radicais a que a pessoa e a dinâmica familiar são submetidas em conseqüência da lesão, acredita-se que a família cria expectativas diante da situação imposta e o LM capta esta expectativa mesmo quando ela não é explicitada. Assim, ao investigar as expectativas do indivíduo com LM foi comum o fato de os mesmos fazerem referência às expectativas de sua família como sendo as suas. Constatou-se que em treze casos $(40,6 \%)$ existe certo conformismo com a situação, pois acreditam não ter nada mais a ser feito e consideram que onde a pessoa com LM está, já é o bastante. Nestes casos, a expectativa é de que o LM consiga se manter estabilizado e sem complicações.

... não tenho expectativas, só se tivesse um jeito para

voltar a andar (sujeito 1).

Algumas pessoas, no entanto (21,9\%), revelaram esperança em melhorar sua qualidade de vida por meio da prática de esportes, conseguindo uma melhor educação intestinal e urinária, conseguindo um acompanhamento em centro de reabilitação, conhecendo mais sobre lesão medular, para poder buscar os recursos existentes e mantendo-se na fisioterapia, para conseguir um tratamento que devolva algum movimento:

A gente sabe que não vai melhorar totalmente, mas a gente espera que eu não fique 24 horas deitado no quarto e quero conseguir uma vaga no SARA (sujeito 22).

... queria deixar de usar fraldas, através de uma melhor educação intestinal e urinária (sujeito 23).

A expectativa de três indivíduos estava mais relacionada com a questão financeira, embora a meta objetiva estivesse relacionada com melhores condições de tratamento.

\section{A mãe sempre fala: queria um bom emprego para dar uma melhor assistência ao AC (sujeito 24).}

... gostaria de poder fazer um plano de saúde (sujeito 16).

Apresentando uma expectativa bastante positiva, seis indivíduos $(18,8 \%)$ referiram que as famílias ainda acreditam que os mesmos voltarão a andar. Além disso, dois indivíduos revelaram esperança de resolução de problemas 
secundários a LM: câncer de bexiga e outro de infecção do trato unirário.

Ao investigar junto aos indivíduos o que seria necessário para melhorar suas condições de vida, constatou-se que onze indivíduos não responderam, mas os demais se manifestaram de forma a ser possível a identificação de quatro grandes grupos de necessidades: a) relacionadas às condições fisiológicas: referido por nove indivíduos (voltar a andar, voltar a ser como antes saudável sem limitações, trabalhar, recuperar-se); b) relacionadas aos serviços de saúde disponíveis: referido por quatro indivíduos (disponibilização gratuita de remédios e materiais e facilidade de acesso a atendimentos especializados como fisioterapeutas, odontólogos, médicos); c) relacionadas ao aparelho social: referido por seis indivíduos (possibilidade de ocupação do tempo, computação, lazer, transporte, infra-estrutura, condições financeiras); d) relacionadas aos recursos tecnológicos e humanos: referido por três indivíduos (cuidador mais presente e cadeira motorizada).

Além da expectativa maior que é a possibilidade de voltar a andar, uma parte considerável dos entrevistados, ao se manifestarem, revelaram deficiência na assistência que recebem dos serviços de saúde e também do Estado em lhes proporcionar melhores condições de vida.

\section{CONSIDERAÇÕES FINAIS}

Com relação às dificuldades que os indivíduos com LM enfrentam no dia-a-dia destacam - se os problemas relacionados à falta de estrutura dos serviços de saúde e o despreparo humano e técnico dos profissionais. Os relatos revelam ainda que após a ocorrência da LM, a família ficou mais unida, demonstrando que as mesmas assumem os cuidados de seus membros dependentes; porém, sentem a ne- cessidade de que os profissionais de saúde tenham um maior preparo para prestar assistência aos indivíduos com este tipo de lesão.

Se a cura não é possível, a abordagem deve ser no sentido de apoiar e fortalecer a família no enfrentamento de suas tarefas diárias, estabelecendo relação de ajuda, no sentido de juntos, profissionais e família, conseguirem alcançar a melhor conduta na assistência aos indivíduos com lesão raquimedular.

Para tanto, necessita-se investir não apenas na formação profissional, no intuito de garantir novas abordagens e novos parâmetros de assistir e cuidar, mas realizar estudos que permitam conhecer com maior profundidade o relacionamento e a situação trazidos pela condição da lesão raquimedular. Incluindo aqui possibilidades de recursos que melhorem a condição de vida dessas pessoas na comunidade de forma a reincidí-las no contexto social e desperte o sentimento de valor, não apenas com relação à reabilitação, mas principalmente estimule a superar as deficiências e lutar pelas expectativas que podem ser realizadas.

Espera-se então, que a partir das questões apresentadas, possa ocorrer sensibilização tanto dos profissionais de saúde quanto dos órgãos governamentais, para que reflitam e contribuam positivamente na busca de um atendimento diferenciado a essa população.

Criem-se novas oportunidades de inserção desses indivíduos na sociedade, tendo-se em mente as suas necessidades humanas básicas. Estas tentativas seriam de grande ajuda na melhoria da qualidade de vida e, na medida do possível, no restabelecimento da cidadania da pessoa com lesão medular, por meio de investimentos no sistema de saúde, tanto na prevenção primária quanto na secundária e terciária.

\section{REFERÊNCIAS}

1. Associação de Assistência a Criança Deficiente (AACD) [home page na Internet]. São Paulo; 2006. [citado 2006 maio 5]. Disponível em: http://www.aacd.org.br/centro_clinicas. asp? sublink2 $=43$.

2. Soares DFPP. Vítimas de acidentes de trânsito ocorridos no perímetro urbano de Maringá, em 1995 [dissertação]. Londrina: Universidade Estadual de Londrina; 1997.

3. Oliveira NLB, Sousa RMC. Motociclistas frente às demais vítimas de acidentes de trânsito no município de Maringá. Acta Sci Health Sc. 2004;26(2):303-10.

4. Soares DFPP. Acidentes de trânsito com vítimas em Maringá PR: análise do perfil epidemiológico e dos fatores de risco de internação e de óbito [tese]. Campinas: Universidade Estadual de Campinas; 2003.
5. Scramin AP. Convivendo com a tetraplegia: da necessidade de cuidados à integralidade no cotidiano de homens com lesão medular cervical [dissertação]. Maringá: Universidade Estadual de Maringá; 2006.

6. Motta MGC. O entrelaçar de mundos: família e hospital: o viver em família e sua interface com a saúde e a doença. Maringá: Eduem; 2002. p. 157-79.

7. Marcon SS, Elsen I. A enfermagem com um novo olhar: a necessidade de enxergar a família. Família Saúde Desenv. 1999; 1(1/2):21-6.

8. Waldow VL. O cuidado na saúde: as relações entre o eu o outro e o cosmos. Petrópolis: Vozes; 2004. 
9. Lima FET, Lopes MVO, Araújo TL. A família como suporte para o idoso no controle da pressão arterial. Família Saúde Desenv. 2001;3(1):63-9.

10. Lacerda MR, Oliniski SR. Familiares interagindo com a enfermeira no contexto domiciliar. Rev Gaúcha Enferm. 2005; 26(1):76-87.

11. Mancussi AC. Assistência ao Binômio paciente/familia na situação de lesão traumática da medual espinhal. Rev Lat Am Enferm. 1998;6(4):67-73.

12. Bardin L. Análise de conteúdo. Lisboa: Edições 70; 1977.

13. Conselho Nacional de Saúde. Resolução n.196, de 10 de outubro de 1996. Diretrizes e normas regulamentadoras de pesquisa envolvendo seres humanos. Bioética. 1996;4(2 Sup) $15-25$.

14. Spòsito MMM, Laredo Filho J, Braga FM, Novo NF. Paraplegia por lesão medular: estudo epidemiológico em pacientes atendidos para reabilitação. Rev Paul Med. 1986; 104(4):196-202.

15. Santos LCR. Lesão traumática da medula espinhal: estudo retrospectivo de pacientes internados no Instituto de Ortopedia e Traumatologia do Hospital das Clínicas da Faculdade de Medicina da Universidade de São Paulo entre 1982 e 1987 [dissertação]. São Paulo: Escola de Enfermagem, Universidade de São Paulo; 1989.

16. Faro ACM. Estudo das alterações da função sexual em homens paraplégicos [dissertação]. São Paulo: Escola de enfermagem, Universidade de São Paulo; 1991.
17. Faro ACM. Do diagnóstico à conduta de enfermagem: a trajetória do cuidar na reabilitação do lesado medular [tese]. São Paulo: Escola de Enfermagem, Universidade de São Paulo; 1995.

18. Loureiro SCC, Faro ACM, Chaves EC. Qualidade de vida sob a ótica de pessoas que apresentam lesão medular. Rev Esc Enferm USP. 1997;31(3):347-67.

19. Prado D. O que é família. São Paulo: Abril Cultural/Brasiliense; 1985.

20. Marcon SS, Lopes MCL, Antunes CRM, Fernandes J, Waidman MAP. Famílias cuidadoras de pessoas com dependência: um estudo bibliográfico. Online Braz J Nurs [periódico na Internet] . 2006 [2006 maio 6]; 5(1) . Disponível em: www.uff.br/nepae/objn201giacomozzietal.htm.

21. Araújo MRN, Sampaio LC, Carneiro MLM, Sena RR. Saúde da família: cuidado no domicílio. Rev Bras Enferm. 2000;53 (n. esp):117-22.

22. Nascimento EM, Silva SM. Em busca de um novo olhar: conhecimento das necessidades das pessoas portadoras de deficiência e mudança de atitude. Rev Bras Saúde Fam. 2002;2(4): $11-2$.

23. Faro ACM. Cuidar do lesado medular em casa: a vivência singular do cuidado familiar [tese]. São Paulo: Escola de Enfermagem, Universidade de São Paulo; 1999.

24. Santos LCR. Re-dimensionando limitações e possibilidades: a trajetória da pessoa com lesão medular traumática [tese]. São Paulo: Escola de Enfermagem, Universidade de São Paulo; 2000. 